this method should not be considered as a contraindication (4).

Conclusions PSB can be safely applied without increasing morbidity and avoiding possible complications that may arise from the results of other anesthesia approaches.

\section{Postoperative pain management}

\section{PAIN MANAGEMENT AFTER COMPLEX SPINE SURGERY: A SYSTEMATIC REVIEW AND PROCEDURE-SPECIFIC POSTOPERATIVE PAIN MANAGEMENT (PROSPECT) RECOMMENDATIONS}

${ }^{1} \mathrm{P}$ Waelkens ${ }^{*},{ }^{2} \mathrm{E}$ Alsabbagh, ${ }^{3} \mathrm{~A}$ Sauter, ${ }^{4} \mathrm{G}$ Joshi, ${ }^{2} \mathrm{H}$ Beloeil. ${ }^{1}$ University Hospitals Leuven, Leuven, Belgium; ${ }^{2} \mathrm{CHU}$ Rennes, Rennes, France; ${ }^{3}$ University of Oslo, Oslo, Norway; ${ }^{4}$ University of Texas Southwestern Medical Center, Dallas, USA

\subsection{6/rapm-2021-ESRA.211}

Background and Aims Complex spinal procedures are associated with intense pain in the postoperative period. Adequate perioperative pain management has been shown to correlate with improved outcomes including early ambulation and discharge. We aimed to evaluate the available literature and develop recommendations for optimal pain management after complex spine surgery.

Methods A systematic review using the PROSPECT methodology was undertaken. RCTs and systematic reviews published in the English language from January 2008 to April 2020 assessing postoperative pain after complex spine surgery using analgesic, anaesthetic or surgical interventions were identified from MEDLINE, EMBASE and Cochrane Databases.

Results Out of 111 eligible studies identified, 31 RCTs and 4 systematic reviews met the inclusion criteria. Preoperative and intraoperative interventions that improved postoperative pain were paracetamol, COX-2 specific-inhibitors or NSAIDs, intravenous ketamine infusion and regional analgesia techniques

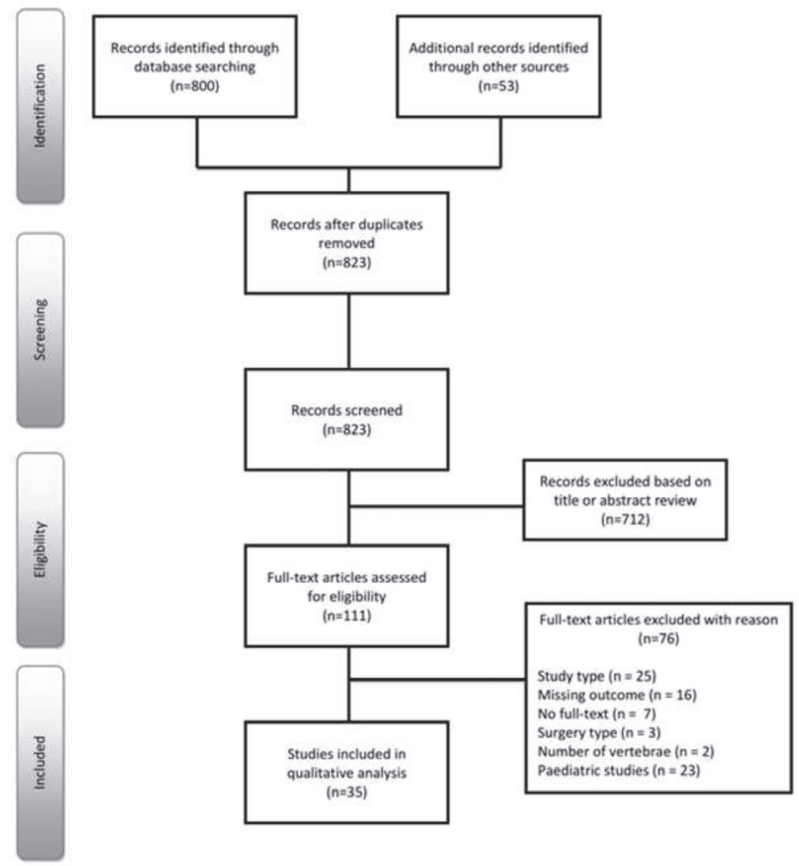

Abstract 211 Figure 1 including epidural analgesia using local anaesthetics with or without opioids. Limited evidence was found for local wound infiltration, intrathecal and epidural opioids, erector spinae plane block, thoracolumbar interfacial plane block, intravenous lidocaine, dexmedetomidine and gabapentin.

Conclusions The analgesic regimen should include preoperative or intraoperative paracetamol and COX-2 specific inhibitors or NSAIDs, continued postoperatively with opioids used as rescue analgesics. Other recommendations are intraoperative ketamine and epidural analgesia using local anaesthetics with or without opioids. Although there is procedure-specific evidence in favour of intraoperative methadone, it is not recommended as it was compared with shorter-acting opioids and due to its limited safety profile. Further qualitative RCTs are required to confirm the efficacy and safety of these recommended analgesics on postoperative pain relief.

\section{IMPACT OF INTRATHECAL DIAMORPHINE IN ENHANCED RECOVERY FOR COLORECTAL SURGERY; OPEN AND LAPAROSCOPIC}

J Luyt* , D Wagstaff, WL Yap. Countess of Chester Hospital, Chester, UK

\subsection{6/rapm-2021-ESRA.212}

Background and Aims There is currently a paucity of evidence in the utility of intrathecal diamorphine for resectional bowel surgery. We audited our departmental practice for perioperative analgesia in the provisions of anaesthesia services for bowel resections.

We looked at the use of a neuraxial block with intrathecal diamorphine, to determine if it has a positive impact on enhanced recovery. Specifically; post-operative opiate requirements, eating and drinking, and mobilising within 24 hours after surgery.

Methods A cohort of randomised patients were selected as per Perioperative Quality Improvement Project (PQIP) data collection protocol from June 2018 to June 2019, 48 patients were eligible. Data was collected from anaesthetic charts, electronic prescribing, and PQIP database. Criteria for data collection included intra- and post-operative analgesia; drinking, eating and mobilising within the first 24 hours of surgery.

Results $77 \%(\mathrm{n}=37)$ of patients received intrathecal diamorphine perioperatively.

Patient controlled analgesia (PCA) morphine consumption is higher on average, $44 \mathrm{mg}$ : $22 \mathrm{mg}$, in non-spinal patients.

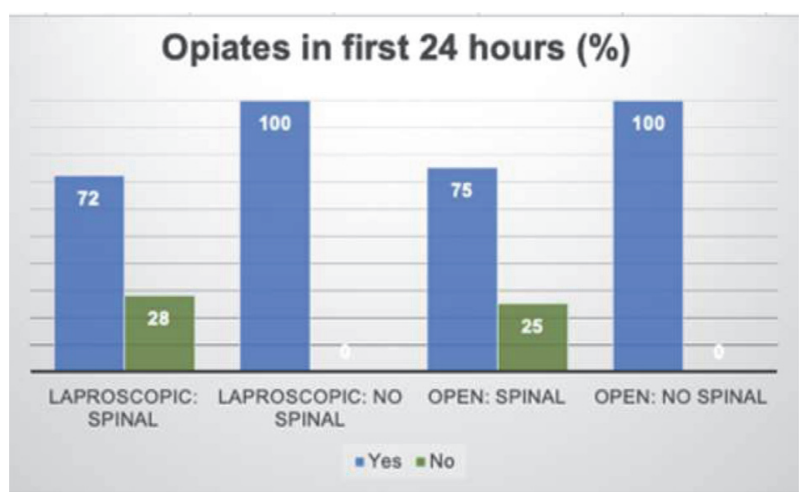

Abstract 212 Figure 1 


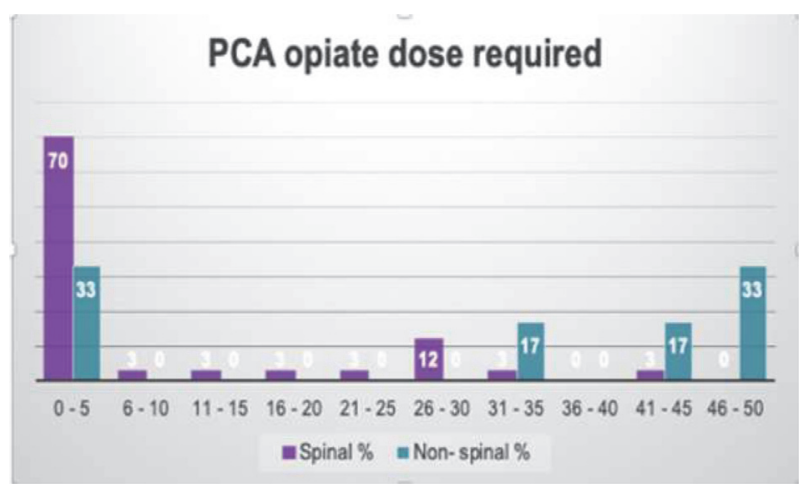

Abstract 212 Figure 2

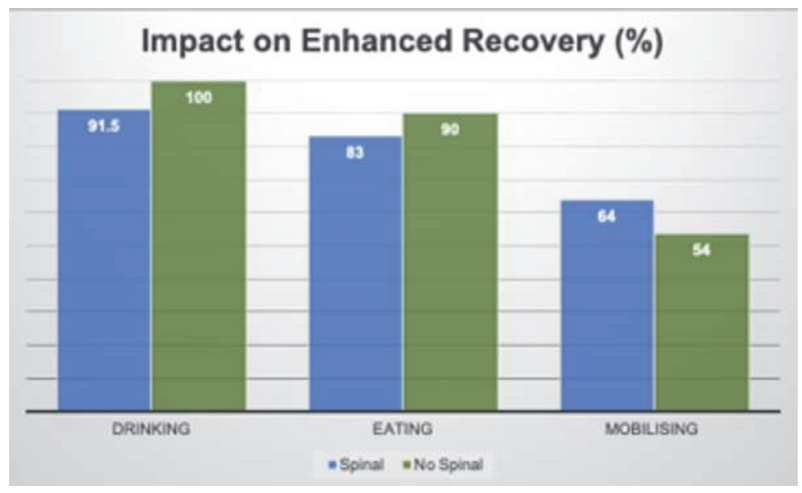

Abstract 212 Figure 3

Conclusions We demonstrated that intrathecal diamorphine reduced post-operative opiate requirements and facilitated earlier mobilisation.

We concluded that the use of intrathecal diamorphine in combination with multimodal analgesia in colorectal surgery is safe and is comparable, if not marginally superior, to PCA in our institution.

We have also shown that despite a wide range of intrathecal diamorphine dosage $(0.5-1 \mathrm{mg})$, there were no post-operative complications which is in keeping with anecdotal experience. Therefore, we feel that intrathecal diamorphine for perioperative analgesia for resectional bowel surgery is a safe and viable technique.

\section{PAIN MANAGEMENT AFTER LAMINECTOMY: A SYSTEMATIC REVIEW AND PROCEDURE-SPECIFIC POST-OPERATIVE PAIN MANAGEMENT (PROSPECT) RECOMMENDATIONS}

${ }^{1} \mathrm{~L}$ Peene ${ }^{*},{ }^{2} \mathrm{P}$ Le Cacheux, ${ }^{3,4} \mathrm{AR}$ Sauter, ${ }^{5} \mathrm{GP}$ Joshi, ${ }^{2} \mathrm{H}$ Beloeil. ${ }^{1}$ University Hospitals Leuven, Leuven, Belgium; ${ }^{2} \mathrm{CHU}$ Rennes, Rennes, France; ${ }^{3}$ Oslo University Hospital, Oslo, Norway; ${ }^{4}$ Inselspital, Bern University Hospital, Bern, Switzerland; ${ }^{5}$ University of Texas Southwestern Medical Center, Dallas, USA

\subsection{6/rapm-2021-ESRA.213}

Background and Aims With lumbar laminectomy increasingly being performed on an outpatient basis, optimal pain management is critical to avoid post-operative delay in discharge and readmission. [1, 4] The aim of this review was to evaluate the available literature and develop recommendations for optimal pain management after one- or two-level lumbar laminectomy.
Methods A systematic review utilizing the PROcedure-SPECific Post-operative Pain ManagemenT (PROSPECT) methodology was undertaken [5]. Randomised controlled trials (RCTs) published in the English language from 1 January 2008 until 31 March 2020 - assessing post-operative pain using analgesic, anaesthetic and surgical interventions - were identified from MEDLINE, EMBASE and Cochrane Databases.

Results Out of 65 eligible studies identified, 39 RCTs met the inclusion criteria. The analgesic regimen for lumbar laminectomy should include paracetamol and a non-steroidal antiinflammatory drug (NSAID) or cyclooxygenase (COX)-2 selective inhibitor administered preoperatively or intraoperatively and continued post-operatively, with post-operative opioids for rescue analgesia. In addition, surgical wound instillation or infiltration with local anaesthetics prior to wound closure is recommended (table 1). Some interventions - gabapentinoids and intrathecal opioid administration - although effective, carry significant risks and consequently were omitted from the recommendations. Other interventions were also not recommended because there was insufficient, inconsistent or lack of evidence (table 2).

Abstract 213 Table 1 Overall recommendations for perioperative pain management in patients undergoing lumbar laminectomy

Preoperative and intraoperative recommendations
Oral or IV paracetamol (Grade D)
Oral or IV NSAIDs/COX-2-specific inhibitors (Grade A)
Surgical wound instillation or infiltration with local anaesth
(Grade A)
Post-operative mcommendations
Oral or IV paracetamol (Grade D)
Oral or IV NSAIDs/COX-2-specific inhibitors (Grade A)
Opioids as rescue medication (Grade D)

COX-2, cyclooxygenase-2; IV, intravenous; NSAIDs, non-steroidal anti-inflammatory drugs

Table 2 Analgesic interventions that are not recommended for pain management in patients undergoing lunbar laminectomy

\begin{tabular}{|c|c|}
\hline Intervention & Reason for not recommending \\
\hline Dexamethasone & $\begin{array}{l}\text { Limited procedure-specific } \\
\text { evidence }\end{array}$ \\
\hline Oral gabapentin/pregabalin & Sig̨nificant risk for adverse effects \\
\hline Intrathecal opioids & Significant risk for adverse effects \\
\hline Epidural analgesia & $\begin{array}{l}\text { Limited procedure-specific } \\
\text { evidence and risk for adverse } \\
\text { effects }\end{array}$ \\
\hline Paravertebral block & $\begin{array}{l}\text { Limited procedure-specific } \\
\text { evidence }\end{array}$ \\
\hline Surgical perineural infiltration & $\begin{array}{l}\text { Limited procedure-specific } \\
\text { evidence }\end{array}$ \\
\hline Surgical wound local infiltration & $\begin{array}{l}\text { Limited procedure-specific } \\
\text { evidence }\end{array}$ \\
\hline Corticosteroids & $\begin{array}{l}\text { Limited procedure-specific } \\
\text { evidence }\end{array}$ \\
\hline Intravenous magnesium & $\begin{array}{l}\text { Lack of procedure-specific } \\
\text { evidence }\end{array}$ \\
\hline Transdermal fentanyl & $\begin{array}{l}\text { Limited procedure-specific } \\
\text { evidence and risk for adverse } \\
\text { effects }\end{array}$ \\
\hline
\end{tabular}

